\title{
(6) OPEN ACCESS \\ Oscillatory whole-body vibration improves exercise capacity and physical performance in pulmonary arterial hypertension: a randomised clinical study
}

\author{
Felix Gerhardt, ${ }^{1}$ Daniel Dumitrescu, ${ }^{1}$ Carina Gärtner, ${ }^{1}$ Ralf Beccard, ${ }^{2}$ \\ Thomas Viethen, ${ }^{1}$ Tilmann Kramer, ${ }^{1}$ Stephan Baldus, ${ }^{1,3}$ Martin Hellmich, ${ }^{4}$ \\ Eckhard Schönau, ${ }^{2}$ Stephan Rosenkranz ${ }^{1,3}$
}

- Additional material is published online only. To view please visit the journal online (http://dx.doi.org/10.1136/ heartjnl-2016-309852).

'Klinik III für Innere Medizin, Herzzentrum der Universität zu Köln, Cologne, Germany ${ }^{2}$ Klinik und Poliklinik für Allgemeine Kinderheilkunde, Universität zu Köln, Cologne, Germany

${ }^{3}$ Cologne Cardiovascular Research Center (CCRC), Heart Center at the University of Cologne, Cologne, Germany ${ }^{4}$ Institut für Medizinische Statistik, Informatik und Epidemiologie, Universität zu Köln, Cologne, Germany

\section{Correspondence to}

Dr Stephan Rosenkranz, Klinik II für Innere Medizin, Herzzentrum der Universität zu Köln,

Kerpener Str. 62, Köln D-50937, Germany; stephan.rosenkranz@ uk-koeln.de

Received 20 April 2016 Revised 23 September 2016 Accepted 29 September 2016 Published Online First 18 January 2017

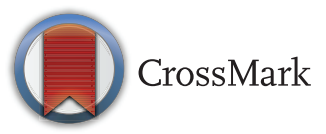

To cite: Gerhardt F, Dumitrescu D, Gärtner C et al. Heart 2017;103:592598

\begin{abstract}
Objective In patients with pulmonary arterial hypertension (PAH), supportive therapies may be beneficial in addition to targeted medical treatment. Here, we evaluated the effectiveness and safety of oscillatory whole-body vibration (WBV) in patients on stable PAH therapy.
\end{abstract}

Methods Twenty-two patients with PAH (mean $P A P \geq 25 \mathrm{~mm} \mathrm{Hg}$ and pulmonary arterial wedge pressure (PAWP) $\leq 15 \mathrm{~mm} \mathrm{Hg}$ ) who were in world health organization (WHO)-Functional Class II or III and on stable PAH therapy for $\geq 3$ months, were randomised to receive WBV (16 sessions of 1 -hour duration within 4 weeks) or to a control group, that subsequently received WBV. Follow-up measures included the 6-min walking distance (6MWD), cardiopulmonary exercise testing (CPET), echocardiography, muscle-power, and health-related quality of life (HRQoL; SF-36 and LPH questionnaires).

Results When compared to the control group, patients receiving WBV exhibited a significant improvement in the primary endpoint, the $6 \mathrm{MWD}(+35.4 \pm 10.9$ vs -4.4 $\pm 7.6 \mathrm{~m})$, resulting in a net benefit of $39.7 \pm 7.8 \mathrm{~m}$ $(p=0.004)$. WBV was also associated with substantial improvements in CPET variables, muscle power, and HRQoL. The combined analysis of all patients $(n=22)$ indicated significant net improvements versus baseline in the 6MWD $(+38.6 \mathrm{~m})$, peakVO2 $(+65.7 \mathrm{~mL} / \mathrm{min})$, anaerobic threshold $(+40.9 \mathrm{~mL} \mathrm{VO} / \mathrm{min})$, muscle power $(+4.4 \%)$, and HRQoL (SF-36 +9.7, LPH -11.5 points) (all $p<0.05)$. WBV was well tolerated in all patients, and no procedure-related severe adverse events (SAES) occurred.

Conclusions WBV substantially improves exercise capacity, physical performance, and HRQoL in patients with PAH who are on stable targeted therapy. This methodology may be utilised in structured training programmes, and may be feasible for continuous long-term physical exercise in these patients.

Trial registration number NCT01763112; Results.

\section{INTRODUCTION}

Despite recent improvements, pulmonary arterial hypertension (PAH) remains a devastating disease, with most patients still harbouring markedly reduced exercise tolerance and limited survival. ${ }^{12}$ Recent randomised controlled trials (RCT) using morbidity/ mortality endpoints demonstrated that novel compounds and combination therapies substantially improve outcome, however significant clinical endpoints occurred in approximately one third of patients even under optimised conditions of combination therapy. ${ }^{3-5}$ Furthermore, many treated patients remain in WHO functional class (WHO-FC) III and exhibit reduced exercise capacity.

In addition to pulmonary vascular disease and concomitant right ventricular dysfunction yielding diminished tissue perfusion and oxygenation during exercise, physical disability is further exacerbated by the lack of physical activity in affected patients. This in turn may have negative impact on hemodynamics and cardiac function, thus indicating the systemic character of PAH. Recent RCTs demonstrated that supervised exercise training is effective in improving exercise capacity, clinical status, and health-related quality of life (HRQoL) in addition to PAH therapies. ${ }^{6-8}$ These effects were associated with improvements in hemodynamics, right ventricle (RV) function, exercise endurance, and survival. ${ }^{9-11}$ Nevertheless, the widespread applicability of training programmes and reliable continuation of exercise beyond the initial training phase remain important challenges.

Oscillatory whole-body vibration (WBV) is a novel exercise modality, which is performed on a vibrating platform that moves in sinusoidal oscillations, and during which static and dynamic exercises can be performed. ${ }^{12}$ Rapid movements of the platform lead to muscle spindle reflexes, which result in reflectory contraction of muscle groups and thus promote gain of muscle strength and power. The most efficient vibration rate enhancing muscle function is $\sim 20 \mathrm{~Hz}$, leading to constant muscle contraction and anaerobic metabolism of the affected muscle fibres. As a consequence, lactate liberation serves as a stimulus for muscle gain. ${ }^{13}$ This methodology has been successfully utilised to enhance moving velocity, muscle power and strength in young athletes, ${ }^{14}$ and to improve physical performance, body balance and HRQoL in elderly patients. ${ }^{15}{ }^{16}$ Furthermore, its application improved exercise capacity, lower limb performance, and HRQoL in patients with chronic diseases such as cystic fibrosis, multiple sclerosis, and chronic obstructive pulmonary disease. ${ }^{17-20}$

Here, we assessed the potential role of oscillatory WBV as a feasible and easily accessible method of continuous and potentially home-based physical exercise in patients with PAH. 


\section{METHODS}

\section{Study population and design}

We prospectively investigated a series of 22 adult patients with stable, symptomatic PAH (Nice group 1, diagnosed by right heart catheterisation (RHC)), who were on stable targeted $\mathrm{PAH}$ therapy for $\geq 3$ months, were in WHO-FC II-III, and had a 6-min walking distance (6MWD) between 50 and $500 \mathrm{~m}$ at screening. Patients were randomised 1:1 to the WBV or control groups. After completion of the initial period, patients in the control group subsequently received WBV in a second phase (figure 1A). Safety follow-up was conducted for 8 weeks after the last WBV. Exclusion criteria were participation in training

A

\section{Study Design}

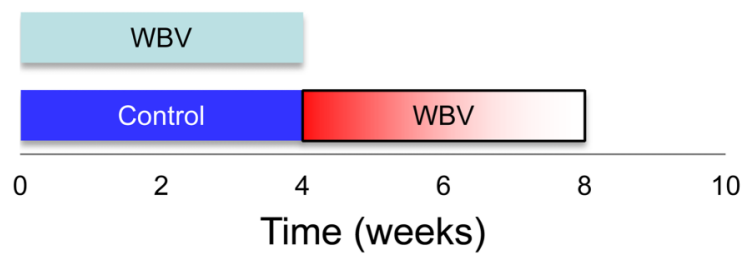

B
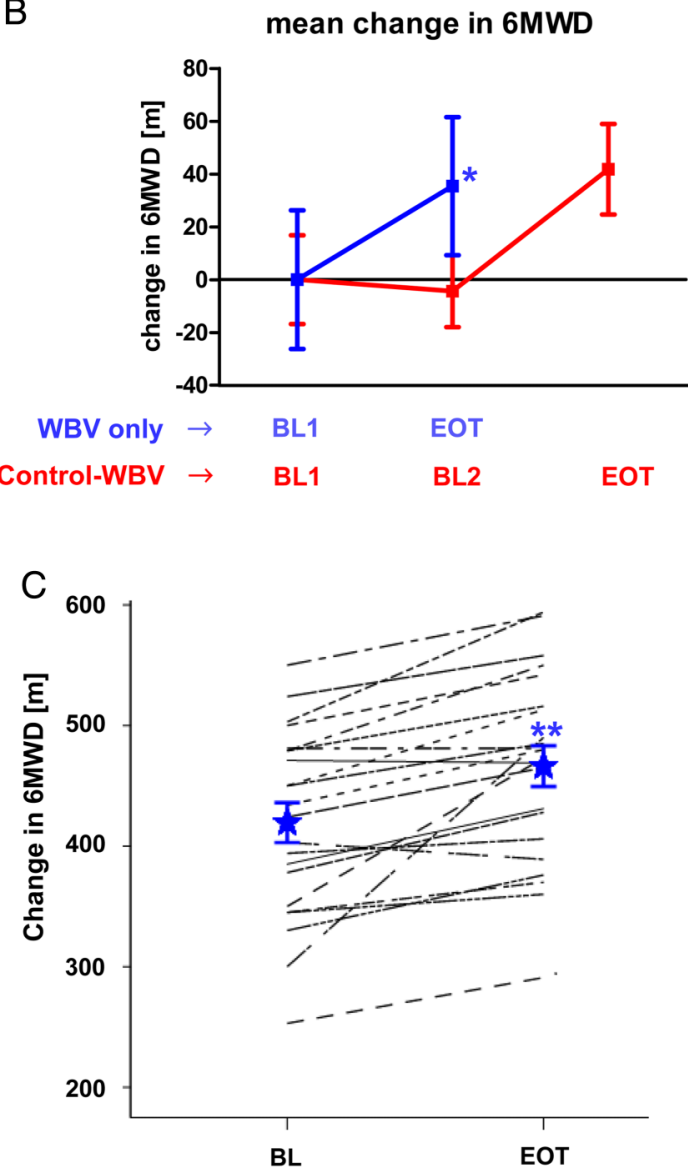

Figure 1 Changes of the 6-min walking distance (6MWD). (A) Study design and treatment groups. (B) Relative change of the 6MWD as compared to baseline 1 in the 'whole-body vibration (WBV) only' and 'Control-WBV' groups ( $n=11$ each) ( $p<0.05$ vs control). (C) Absolute values and change of the 6MWD at end of WBV versus baseline in the entire cohort $(n=22)$. Data represent mean values \pm standard error of the mean (SEM) ${ }^{*} p<0.01$ vs control ${ }^{*} p<0.001$ vs baseline. programmes within 3 months prior to screening, physical inability to perform WBV, pregnancy, osteoporosis, acute thrombosis, hip or knee implants, and recent fractures or injuries ( $<6$ months). The study was approved by the local Ethics Committee, and all patients gave written informed consent.

\section{Oscillatory whole-body vibration}

WBV was performed on a side-alternating Galileo MedM platform (Novotec Medical GmbH, Pforzheim, Germany), utilising a vibration frequency of $20 \mathrm{~Hz}$ and a peak-to-peak displacement of $20 \mathrm{~mm}$, as previously described. ${ }^{21}$ WBV was performed during 16 sessions of 1 -hour duration within 4 weeks, and was accompanied by a standardised exercise protocol, where patients were instructed to perform specific exercises on the platform to promote muscle coordination, using a pictorial. Patients were instructed by an experienced physical therapist throughout the procedure.

\section{Right heart catheterisation}

$\mathrm{PAH}$ was confirmed by RHC in all patients, defined by a mean pulmonary artery pressure (PAP) of $\geq 25 \mathrm{~mm} \mathrm{Hg}$ and a pulmonary arterial wedge pressure $(\mathrm{PAWP}) \leq 15 \mathrm{~mm} \mathrm{Hg}$ at rest. ${ }^{1} \mathrm{RHC}$ was carried out in a standardised fashion according to current recommendations. ${ }^{22}{ }^{23}$ Left heart or chronic lung disease were routinely ruled out, and chronic thromboembolic pulmonary hypertension $(\mathrm{PH})$ was excluded in all patients. ${ }^{1} 23$

\section{Echocardiography}

Transthoracic echocardiography was performed using the Philips iE 33 system (Philips GmbH, Hamburg, Germany). Assessments of the right heart included right atrial area, right ventricular end-diastolic diameter (RVEDD), tricuspid annular plane systolic excursion (TAPSE), and tricuspid regurgitation velocity (TRV). The systolic tricuspid pressure gradient $\left(\Delta \mathrm{P}_{\max } \mathrm{TV}\right)$ was calculated from TRV by the modified Bernoulli equation, and pulmonary arterial systolic pressure (PASP) was estimated as the sum of $\Delta \mathrm{P}_{\max } \mathrm{TV}$ and right atrial pressure. All measurements were performed according to current guidelines. ${ }^{24}$

\section{Six-min walking test}

Submaximal exercise capacity was evaluated by the 6-min walking test, which was performed in a standardised way according to the guidelines of the American Thoracic Society. ${ }^{25}$

\section{Cardiopulmonary exercise testing}

CPET was performed with semi-recumbent cycling on a stationary cycle ergometer. Gas exchange was measured breath-by-breath, using a Care Fusion Masterscreen/cardiopulmonary exercise test (CPX) metabolic cart (CareFusion Inc., Switzerland) as previously described. ${ }^{26}$ The anaerobic threshold (AT) was determined from gas exchange by the V-slope method. Nadir minute volume (VE)/ $\mathrm{VCO}_{2}$ was defined as the lowest $\mathrm{VE} / \mathrm{VCO}_{2}$ value reached during the incremental exercise phase. Peak $\mathrm{P}_{\mathrm{ET}} \mathrm{CO}_{2}$ was defined as the highest value reached during the incremental exercise phase.

\section{Assessment of muscle strength and coordination}

To assess kinetic parameters of muscle function and coordination, patients performed the single two leg jump (S2LJ) and the chair rising test (CRT) before and after WBV. Functional parameters were assessed by mechanography utilising the Leonardo platform (Novotec Medical GmbH, Pforzheim, Germany). ${ }^{27}$ Kinetic parameters were calculated in relation to body weight. 
S2LJ-The jump was performed as a counter-movement jump using both feet with freely moving arms, and individuals were instructed to jump as high as possible. The maximal force of the ascending part of the jump was used for further calculations and is defined as peak jump velocity (PJV), whereas the peak of the calculated power (force $\times$ velocity) is expressed as peak jump power (PJP).

CRT - A module to sit on was installed on the platform, and individuals were instructed to perform five repetitions from the sitting to standing position, without using their hands. The maximal force to get up out of the sitting position was measured and used for further calculation.

\section{Health-related quality of life}

HRQoL was assessed by the SF-36 (100 point-scale) and Living with Pulmonary Hypertension (LPH; 105 point-scale) questionnaires, respectively. For the SF-36, scores range from 0 to 100 , and lower scores indicate worse HRQoL. The LPH questionnaire is based on the Minnesota Living with Heart Failure Questionnaire (MLHFQ), but was specifically adapted and evaluated for patients with PAH. Scores range from 0 to 105 , and higher scores indicate worse HRQoL.

\section{Statistical analysis}

Wilcoxon rank-sum test was performed to compare the mean overall treatment effect of WBV on the 6MWD between groups. To assess the change in HRQoL and NTproBNP serum levels, a paired samples t-test was used. All data are presented as mean values \pm standard deviation (SD) or standard error of the mean (SEM), as indicated. A p value $<0.05$ was considered as statistically significant. Analyses were performed with SPSS V.10.0 (SPSS Inc., Chicago, Illinois, USA).

\section{RESULTS}

\section{Patient characteristics}

Demographics and disease characteristics at baseline are summarised in tables 1 and 2. PAH was of idiopathic or hereditary origin, or associated with connective tissue disease or corrected congenital heart disease. All patients were in WHO-FC II or III, and were on stable doses of targeted PAH therapy with endothelin receptor antagonists (ERA), phosphodiesterase type-5 (PDE5) inhibitors, soluble guanylate-cyclase (sGC) stimulators, tyrosine kinase inhibitors, or inhaled or parenteral prostanoids for $\geq 12$ weeks prior to the intervention.

Whole-body vibration improves exercise capacity and HRQoL Patients were randomised 1:1 to receive WBV or to a control group (figure 1A). When compared to the control group, patients receiving WBV exhibited a significant net improvement in the primary outcome measure, $6 \mathrm{MWD}$, at the end of the 4 week period of $+39.8 \mathrm{~m}(+35.4 \pm 10.6 \mathrm{~m}$ vs $-4.4 \pm 7.6 \mathrm{~m}$; $\mathrm{p}=0.004$ ) (figure 1B). All patients randomised to the control group subsequently received WBV in a second phase. One patient in the initial control group exhibited a substantial decline of the $6 \mathrm{MWD}$ at baseline 2 due to acute back pain. In this case, the value obtained at baseline 1 was carried forward. In the initial control group, there was also a significant increase of the $6 \mathrm{MWD}$ by $41.8 \pm 7.9 \mathrm{~m}$ at the end of WBV versus baseline $2(p<0.05)$ (figure 1B). The combined analysis of the whole cohort $(n=22)$ indicated that WBV was associated with a significant improvement of the 6MWD versus baseline of +38.6 $\pm 6.6 \mathrm{~m}(\mathrm{p}<0.001)$ (figure $1 \mathrm{C})$.

WBV was also associated with an enhanced maximal exercise tolerance as indicated by an increase of peakVO $2(1006.1 \pm 61.1$ vs $940.4 \pm 54.1 \mathrm{~mL} / \mathrm{min}$ at baseline; $\mathrm{p}<0.05$; mean increase $65.7 \mathrm{~mL} / \mathrm{min}$ ) during CPET (figure 2A). Furthermore, WBV improved the limit of permanently sustainable exercise as assessed by the oxygen uptake at the anaerobic threshold (762.0 \pm 35.4 vs $721.1 \pm 37.8 \mathrm{mLVO}_{2} / \mathrm{min}$ at baseline, $\mathrm{p}<0.05$; mean increase $40.9 \mathrm{mLVO}_{2} / \mathrm{min}$ ) (figure $2 \mathrm{~B}$ ), indicating an improved aerobic metabolism during exercise after WBV. In contrast, ventilatory efficiency in terms of the nadir $\mathrm{VE} / \mathrm{VCO}_{2}$ ratio and peakP $\mathrm{P}_{\mathrm{ET}} \mathrm{CO}_{2}$ during exercise did not show significant differences after WBV as compared to baseline (see online supplementary

Table 1 Demographics, disease characteristics at baseline and aetiology of pulmonary arterial hypertension (PAH) in 22 patients undergoing oscillatory whole-body vibration (WBV) in the 'WBV only' and 'Control-WBV' (initial control, subsequent WBV) groups

\begin{tabular}{|c|c|c|c|c|}
\hline & WBV only ( $n=11)$ & Control-WBV $(n=11)$ & All $(n=22)$ & $p$ Value (A vs B) \\
\hline \multicolumn{5}{|l|}{ Patient demographics } \\
\hline Age, mean (range) & $65.1 \pm 5.0(27-83)$ & $46.0 \pm 3.7(27-65)$ & $55.6 \pm 3.7(27-83)$ & 0.006 \\
\hline Mean age at diagnosis & $62.0 \pm 5.6$ & $43.4 \pm 4.0$ & $52.7 \pm 3.9$ & 0.009 \\
\hline Disease duration (years) & $2.6 \pm 0.6$ & $3.1 \pm 0.8$ & $2.8 \pm 0.7$ & 0.809 \\
\hline Female/male $(n, \%)$ & $7(64) / 4(36)$ & $6(55) / 5(45)$ & $13(59) / 9(41)$ & 1.000 \\
\hline BMI $\left(\mathrm{kg} / \mathrm{cm}^{2}\right)$ & $24.8 \pm 1.1$ & $26.4 \pm 2.0$ & $25.6 \pm 1.1$ & 0.562 \\
\hline \multicolumn{5}{|l|}{ Disease characteristics } \\
\hline WHO-FC II (n, \%) & $6(55)$ & 7 (64) & $13(59)$ & 1.000 \\
\hline WHO-FC III (n, \%) & $5(45)$ & $4(36)$ & $9(41)$ & 1.000 \\
\hline $6 \mathrm{MWD}(\mathrm{m})$ & $398.5 \pm 26.2$ & $456.9 \pm 13.6$ & $427.7 \pm 15.8$ & 0.067 \\
\hline Borg score & $3.5 \pm 0.5$ & $3.3 \pm 0.5$ & $3.4 \pm 0.3$ & 0.264 \\
\hline $\mathrm{FEV}_{1}$ (\% pred.) & $84.8 \pm 3.5$ & $81.2 \pm 5.5$ & $83.0 \pm 3.2$ & 0.811 \\
\hline FVC (\% pred.) & $89.9 \pm 3.4$ & $86.5 \pm 4.2$ & $88.2 \pm 2.7$ & 0.699 \\
\hline \multicolumn{5}{|l|}{ Aetiology of PAH } \\
\hline Idiopathic PAH (n, \%) & 7 (64) & $7(64)$ & $14(64)$ & 1.000 \\
\hline \multicolumn{5}{|l|}{ PAH associated with: } \\
\hline CTD $(n, \%)$ & $4(36)$ & $2(18)$ & $6(27)$ & 1.000 \\
\hline Other $(n, \%)$ & - & $2(18)$ & $2(9)$ & 1.000 \\
\hline
\end{tabular}

Values represent numbers of patients $(n, \%)$ or mean values $\pm S D$

BMI, body mass index; CTD: Connective tissue disease; FVC, functional vital capacity; 6MWD, 6-min walking distance; SD, standard deviation; WHO-FC, WHO functional class. 
Table 2 Pulmonary hemodynamics at baseline and targeted pulmonary arterial hypertension (PAH) therapy in twenty-two patients with PAH undergoing oscillatory whole-body vibration (WBV) in the "WBV only" and "Control-WBV" (initial control, subsequent WBV) groups

\begin{tabular}{|c|c|c|c|}
\hline & $\begin{array}{l}\text { WBV only } \\
(n=11)\end{array}$ & $\begin{array}{l}\text { Control-WBV } \\
(n=11)\end{array}$ & $\begin{array}{l}\text { All } \\
(n=22)\end{array}$ \\
\hline \multicolumn{4}{|l|}{ Hemodynamics } \\
\hline PAP systolic (mm Hg) & $58.5 \pm 8.4$ & $64.5 \pm 5.5$ & $61.5 \pm 4.9$ \\
\hline PAP diastolic (mm Hg) & $20.7 \pm 2.6$ & $25.6 \pm 3.1$ & $23.2 \pm 2.1$ \\
\hline PAP mean $(\mathrm{mm} \mathrm{Hg})$ & $35.5 \pm 4.2$ & $41.9 \pm 3.6$ & $38.7 \pm 2.8$ \\
\hline PAWP (mm Hg) & $11.1 \pm 1.1$ & $9.3 \pm 1.1$ & $10.2 \pm 0.8$ \\
\hline TPG (mm Hg) & $24.7 \pm 4.6$ & $33.2 \pm 3.3$ & $28.9 \pm 2.9$ \\
\hline DPG (mm Hg) & $9.6 \pm 3.0$ & $16.4 \pm 2.8$ & $13.0 \pm 2.1$ \\
\hline Cardiac output (L/min) & $4.3 \pm 0.2$ & $4.6 \pm 0.3$ & $4.5 \pm 0.2$ \\
\hline Cardiac index $\left(L / \mathrm{min} / \mathrm{m}^{2}\right)$ & $2.4 \pm 0.1$ & $2.5 \pm 0.1$ & $2.4 \pm 0.1$ \\
\hline PVR (WU) & $5.8 \pm 0.9$ & $7.6 \pm 1.1$ & $6.7 \pm 0.7$ \\
\hline \multicolumn{4}{|l|}{ Targeted PAH therapy } \\
\hline PDE5i monotherapy $(n, \%)$ & $6(55)$ & $1(9)$ & $7(32)$ \\
\hline ERA+PDE5i (n, \%) & $2(18)$ & $5(46)$ & $7(32)$ \\
\hline$E R A+s G C-S(n, \%)$ & $1(9)$ & $2(18)$ & $3(14)$ \\
\hline ERA+PDE5i+PCA $(n, \%)$ & $1(9)$ & $2(18)$ & $3(14)$ \\
\hline PDE5i+TKI (n, \%) & 0 & 1 (9) & $1(4)$ \\
\hline ERA+PDE5i+TKI $(n, \%)$ & $1(9)$ & 0 & $1(4)$ \\
\hline \multicolumn{4}{|c|}{$\begin{array}{l}\text { Values represent numbers of patients }(\mathrm{n}, \%) \text { or mean values } \pm \text { SEM. } \\
\text { DPG, diastolic pressure gradient (=PAPdiast - PAWP); ERA, Endothelin receptor } \\
\text { antagonist; PAP, Pulmonary artery pressure; PAWP, Pulmonary arterial wedge } \\
\text { pressure; PCA, Prostanoid; PDESi, Phosphodiesterase type } 5 \text { inhibitor; PVR, } \\
\text { Pulmonary vascular resistance (=TPG/CO); SEM, standard error of the mean; } \\
\text { sGC-S, soluble guanylate cyclase stimulator; TKI, Tyrosine kinase inhibitor; TPG, } \\
\text { transpulmonary pressure gradient (=PAPmean-PAWP). }\end{array}$} \\
\hline
\end{tabular}

figure 1), indicating that WBV did not alter the structural changes in the pulmonary circulation, that lead to impaired ventilation/perfusion matching during exercise.

HRQoL was assessed by utilising the SF-36 and LPH questionnaires, respectively. During phase 1 , there was a significant increase of the total SF-36 score, as well as the physical and mental scores, after 4 weeks in the WBV group, when compared to the control group (table 3). In the combined analysis of all patients $(n=22)$, there was also a significant increase of the total SF-36 score from $54.7 \pm 3.3$ at baseline to $66.7 \pm 3.6$ at the conclusive follow-up visit at 4 weeks, translating into a mean increase of $9.7 \pm 2.5$ points $(\mathrm{p}=0.001)$ (table 3). Furthermore, the physical dimension score $(49.8 \pm 2.3$ to $59.0 \pm 3.5)$ and emotional dimension score $(56.0 \pm 4.2$ to $68.3 \pm 3.7)$ showed significant improvements, respectively.

The LPH questionnaire led to similar results: After 4 weeks of WBV, the total LPH score decreased from $26.2 \pm 6.1$ to 17.6 \pm 6.0 points (versus $41.2 \pm 6.1$ to $40.1 \pm 4.9$ in the control group), and this was due to improvements of both physical and emotional status (see online supplementary table 1). Likewise, the pooled analysis of all 22 patients revealed significant decreases of the total LPH score (33.7 \pm 3.7 to $22.3 \pm 3.6$ ), physical dimension score $(16.7 \pm 1.4$ to $11.7 \pm 1.0)$, and emotional dimension score $(7.3 \pm 1.6$ to $4.3 \pm 1.2)$ after WBV versus baseline (see online supplementary table 1 ).

\section{Impact of WBV on kinetic parameters of muscle strength and function}

When kinetic parameters of muscle strength and coordination were assessed with the S2LJ and the CRT, WBV led to improvements of muscle power and force, as well as contraction velocity. Patients receiving WBV showed an increase in the PJP of $4.4 \pm 1.6 \%$ after 4 weeks versus baseline. This finding indicates an improvement of motoric performance, which is due to both a decline in the force needed to perform the test by 2.7 $\pm 1.2 \%$ after $\mathrm{WBV}$, and an increase of the contraction velocity by $3.3 \pm 1.4 \%$. In the CRT, attention was given to changes in velocity. This was captured by measuring the average time per test. Compared to baseline the overall time needed to perform this test after WBV was $0.6 \mathrm{~s}$ faster (not shown).

\section{Echocardiographic parameters and NTproBNP levels}

There were no changes in echocardiographic parameters between groups including right atrium (RA) area, RVEDD, $\Delta \mathrm{P}_{\max } \mathrm{TV}$, and TAPSE during the observation period of 4 weeks (table 4). Likewise, no significant changes in NTproBNP levels were observed $(882.2 \pm 275.8 \mathrm{ng} / \mathrm{L}$ at end of WBV vs 996.0 $\pm 318.1 \mathrm{ng} / \mathrm{L}$ at baseline, n.s.).

\section{Safety and tolerability}

WBV was well tolerated in all patients, and no procedure-related serious adverse events occurred. Also, no adverse events (AEs) occurred during the WBV procedure itself. AEs occurring during the 4-week WBV period included sore muscles and in one case back pain (table 5). Another case of acute back pain was recorded in the control phase of the initial control group. No additional AEs were recorded during the safety assessment up to 8 weeks after WBV.

\section{DISCUSSION}

In this pilot study, WBV improved exercise capacity, HRQoL, and muscle strength/coordination in patients with PAH. WBV was well tolerated and not associated with significant AEs. Our data thus provide proof-of-concept for the efficacy and safety of WBV in patients with PAH who are on stable targeted therapy.

To our knowledge, our study was the first to investigate WBV in patients with PAH. The fact that WBV improves exercise tolerance and capacity in PAH patients is consistent with previous reports on the effects of training and rehabilitation programmes in such patients, which have demonstrated meaningful improvements of exercise capacity and endurance, clinical status, HRQoL, hemodynamics, RV function, and survival. ${ }^{6-11}$ Consequently, supervised exercise training is recommended as supportive therapy for PAH patients in current guidelines. ${ }^{1}$ Thus, our results are in line with the concept that physical exercise is an effective adjunct to medical therapy in PAH. From a practical point of view, however, the feasibility of long-term exercise is critical for its long-term benefit. In this regard, WBV may represent a valuable tool to provide sustainable exercise modalities.

An important consideration is whether the magnitude of the observed improvements obtained by WBV is of clinical relevance. As reported herein, a 4-week period of WBV was associated with a significant augmentation of exercise capacity, as assessed by the 6MWD and CPET. This was accompanied by a substantial improvement of HRQoL. A recent study using distributional and anchor-based methods indicated that the estimated minimal clinically important difference in the 6MWD for PAH patients is $33 \mathrm{~m} .{ }^{28}$ Herein, the net improvement of the 6MWD by WBV was $39.8 \mathrm{~m}$. This treatment effect even exceeded the 6MWD improvement of novel targeted PAH therapies that were observed in recent clinical trials. ${ }^{3} 529$ Likewise, the improvements in HRQoL also exceeded the effects captured in the trials investigating novel medical treatments. Thus, the improvements 

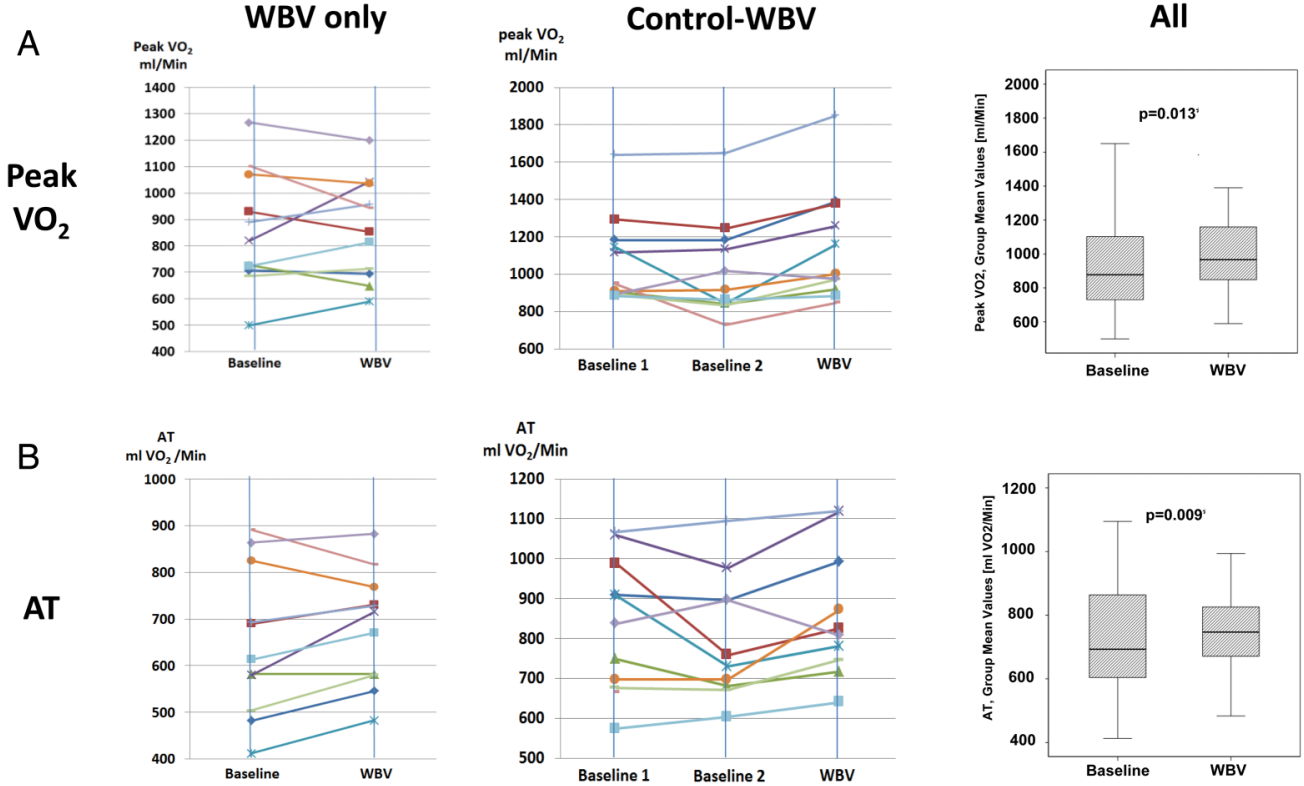

Figure 2 Key exercise gas exchange parameters obtained by cardiopulmonary exercise testing. Left and middle column: Display of all cases before and after 'Whole-Body Vibration' (WBV) in the 'WBV only' and 'Control-WBV' groups (each $n=11)$. Box plots show the whole cohort $(n=22)$ at baseline and at end of WBV. (A) Peak $\mathrm{VO}_{2}$. (B) Anaerobic threshold (AT). $\mathrm{VO}_{2}$, Oxygen uptake; AT, Anaerobic threshold.

Table 3 Impact of whole-body vibration (WBV) on health-related quality of life (HRQoL)

\begin{tabular}{|c|c|c|c|c|c|}
\hline & BL 1 & BL 2 & EOT & p Value (BL 1 vs EOT) & $p$ Value (BL 2 vs EOT) \\
\hline \multicolumn{6}{|l|}{ WBV only } \\
\hline Total score & $56.8 \pm 4.8$ & - & $64.2 \pm 6.4$ & 0.061 & \\
\hline Physical dimension score & $50.7 \pm 3.3$ & - & $56.1 \pm 6.2$ & 0.326 & \\
\hline Emotional dimension score & $59.8 \pm 6.5$ & - & $67.4 \pm 6.6$ & 0.016 & \\
\hline \multicolumn{6}{|l|}{ Control-WBV } \\
\hline Total score & $52.5 \pm 4.8$ & $57.4 \pm 3.8$ & $69.2 \pm 3.3$ & & 0.008 \\
\hline Physical dimension score & $48.8 \pm 3.3$ & $53.4 \pm 3.5$ & $61.8 \pm 3.6$ & & 0.057 \\
\hline \multirow[t]{2}{*}{ Emotional dimension score } & $52.3 \pm 5.4$ & $55.6 \pm 4.3$ & $69.3 \pm 3.5$ & & 0.001 \\
\hline & BL & & EOT & p Value (BL vs EOT) & \\
\hline \multicolumn{6}{|l|}{ All } \\
\hline Total score & $54.7 \pm 3.3$ & - & $66.7 \pm 3.6$ & 0.001 & \\
\hline Physical dimension score & $49.8 \pm 2.3$ & - & $59.0 \pm 3.5$ & 0.014 & \\
\hline Emotional dimension score & $56.0 \pm 4.2$ & - & $68.3 \pm 3.7$ & $<0.0001$ & \\
\hline
\end{tabular}

of the 6MWD, CPET parameters and HRQoL in the present study should indeed be judged as clinically meaningful.

Overall, the studied sample represents a group of patients with well controlled $\mathrm{PAH}$, who mostly received combination therapy for PAH and were in stable condition. Nevertheless, such patients frequently display reduced physical activity, which in turn accelerates the burden on the cardiopulmonary system. It is quite remarkable that substantial improvements of nearly all measured variables were achieved within 4 weeks of WBV. This is consistent with findings in healthy males, in whom the heart rate response to WBV and the increase in blood lactate levels showed a rapid decline within a few days of $\mathrm{WBV}^{30}$ Furthermore, our results are consistent with the effects of WBV in individuals with other conditions. ${ }^{15-20}$ Moreover, a recent RCT demonstrated that the complimentary use of WBV improved the rehabilitation results in patients after lung transplantation. ${ }^{31}$
From our study, it is not entirely clear how WBV improves exercise capacity in $\mathrm{PAH}$. The interpretation of CPET parameters may give insight on the underlying pathophysiology. According to the Fick equation, oxygen uptake is determined by the product of $\mathrm{CO}$ and the oxygen content difference between arterial and mixed venous blood $\left(\mathrm{C}_{\mathrm{a}-\mathrm{v}} \mathrm{O}_{2}\right)$. While an increase in $\mathrm{CO}$ indicates hemodynamic improvement, an increase in $\mathrm{C}_{\mathrm{a}-\mathrm{v}} \mathrm{O}_{2}$ indicates exhausted peripheral $\mathrm{O}_{2}$-extraction. With this study-design, an allocation to one specific mechanism of improvement is impossible. However, a significant increase in peakVO $\mathrm{V}_{2}$ indicates that the product of a higher $\mathrm{CO}$ and an improved peripheral $\mathrm{O}_{2}$-extraction at a given work rate are accountable for the improvements. Our findings are consistent with the previous observation that a structured rehabilitation programme improves maximal and submaximal exercise capacity, however without significant changes in ventilatory efficiency and pulmonary hemodynamics. ${ }^{6}$ 
Table 4 Echocardiographic parameters at baseline and at the end of the whole-body vibration (WBV) period in the 'WBV only' and 'Control-WBV' (initial control, subsequent WBV) groups

\begin{tabular}{llll}
\hline & $\begin{array}{l}\text { WBV only } \\
(\mathbf{n}=11)\end{array}$ & $\begin{array}{l}\text { Control-WBV } \\
(\mathbf{n}=11)\end{array}$ & All $(\mathbf{n}=22)$ \\
\hline RA area, $\mathrm{cm}^{2}$ & & & \\
$\quad$ Baseline & $20.8 \pm 1.4$ & $21.4 \pm 3.7$ & $21.1 \pm 1.9$ \\
$\quad$ EOS & $22.9 \pm 1.7$ & $22.1 \pm 3.8$ & $22.5 \pm 1.9$ \\
RVEDD, mm & & & \\
$\quad$ Baseline & $39.2 \pm 1.7$ & $42.2 \pm 2.2$ & $40.7 \pm 1.3$ \\
$\quad$ EOS & $35.6 \pm 1.9$ & $41.6 \pm 2.6$ & $40.1 \pm 1.5$ \\
$\begin{array}{l}\Delta P_{\text {max }} T \text { TV, mmHg } \\
\text { Baseline }\end{array}$ & $50.7 \pm 4.9$ & $50.2 \pm 3.9$ & \\
$\quad$ EOS & $44.1 \pm 4.5$ & $51.2 \pm 4.1$ & $40.5 \pm 3.7$ \\
TAPSE, mm & & & \\
$\quad$ Baseline & $18.0 \pm 0.9$ & $19.9 \pm 1.5$ & $19.0 \pm 3.9$ \\
EOS & $18.8 \pm 0.6$ & $19.8 \pm 0.8$ & $19.3 \pm 0.6$ \\
\hline
\end{tabular}

All values represent means \pm SEM

EOS, end of study; RA area, Right atrial area; RVEDD, Right ventricular end-diastolic diameter; SEM, standard error of the mean; TAPSE, Tricuspid annular plane systolic excursion; $\Delta \mathrm{P}_{\max } \mathrm{TV}$, Systolic trans-tricuspid valve pressure gradient.

Table 5 Adverse events that occurred in the entire study period in the 'whole-body vibration (WBV) only' and 'Control-WBV' (initial control, subsequent WBV) groups ( $n=11$ each), as well as in the entire cohort $(n=22)$

\begin{tabular}{llll}
\hline & WBV only $(\mathrm{n}=1 \mathbf{1 1})$ & Control-WBV $(\mathrm{n}=11)$ & All $(\mathrm{n}=\mathbf{2 2})$ \\
\hline Adverse events & & & \\
Sore muscles $(\mathrm{n}, \%)$ & $3(27)$ & $5(46)$ & $8(36)$ \\
Back pain $(\mathrm{n}, \%)$ & $1(9)$ & 0 & $1(9)$ \\
Dizziness $(\mathrm{n}, \%)$ & 0 & 0 & 0 \\
Syncope $(\mathrm{n}, \%)$ & 0 & 0 & 0 \\
\hline
\end{tabular}

A further insight may be derived from the analysis of peripheral muscle function. Both the S2LJ and CRT revealed that WBV improved muscle contraction velocity, thereby reducing the force that is necessary to achieve a certain power level. The higher velocity allows more secure movement and improved neuromuscular coordination, which is critical for motoric performance. $^{32}$ Additionally, the combination of exercise and respiratory training was shown to improve respiratory muscle function. ${ }^{33}$ In the long run, these effects are expected to ease the burden of chronic diseases on the cardiopulmonary system. In that sense, WBV may represent a training tool with an optimised balance between training stimulus for the muscle and the corresponding load on the heart and circulatory system. Since PAH patients often display substantial deconditioning due to circulatory impairment and sedentarism, this exercise modality is likely able to achieve targeted restoration of muscle function.

\section{Limitations}

Our study should be considered a controlled pilot study in a limited number of patients, yet it is the first examining the potential value of WBV in PAH. Although we performed a randomised controlled study, the intervention and control groups were not entirely matched with respect to age, disease severity, functional capacity, and hemodynamic impairment. While this is likely due to the small sample size, it should be acknowledged that the treatment effect was not only observed between groups in phase 1 , but also within both groups alone, when the measures after 4 weeks of WBV were compared to baseline. Consequently, the combined analysis of the entire cohort showed remarkable improvements in exercise capacity and HRQoL. A potential confounder is the lack of blinding, which is however not feasible in such a study.

Further limitations are the limited time period during which WBV was performed, and the limited observation time. We do not know whether a ceiling effect was reached after 4 weeks, or whether maintenance of WBV for longer periods of time may have led to even more pronounced improvement of the outcome measures. Furthermore, it remains unclear how long the beneficial effects of WBV may last once WBV is stopped, or whether repetitive periods of WBV would be sufficient to maintain a therapeutic effect. While the current information is limited, our data seem sufficient to support continued investigation of WBV in larger scale studies which are currently under way.

\section{CONCLUSIONS}

This randomised, controlled pilot intervention study shows that WBV is well tolerated in stable PAH patients and provides significant benefit on exercise capacity, physical performance and HRQoL, when provided in addition to targeted PAH therapies. These benefits warrant further controlled studies to assess the value of WBV as supplementary therapy for an extended population of PAH patients. Potentially, WBV may be included in structured training and rehabilitation concepts, and may be further utilised for continuous long-term, home-based physical exercise in these patients.

\section{Key messages}

What is already known on this subject?

Despite recent improvements, pulmonary arterial hypertension (PAH) remains a serious and progressive condition that is associated with high morbidity and mortality. Supportive therapies including exercise training programmes may be beneficial in addition to targeted medical treatment.

\section{What might this study add?}

This randomised, controlled, open-label pilot study shows that oscillatory whole-body vibration (WBV), performed on a resting physical exercise platform, is a safe and effective treatment in PAH patients who are on stable targeted medical therapy. WBV substantially improved exercise capacity as assessed by the 6-min walking distance and cardiopulmonary exercise testing, and furthermore improved peripheral muscle function and health-related quality of life within 4 weeks.

\section{How might this impact on clinical practice?}

These data suggest that WBV is a promising adjunct to medical therapy in PAH. Potentially, WBV may be included in structured training and rehabilitation concepts, and may be further utilised for continuous long-term, home-based physical exercise in these patients.

Acknowledgements This work was supported by a research grant from Actelion Pharmaceuticals Deutschland (Freiburg, Germany). The company was not involved in study design, data collection or analyses. The technical support provided by Linda Nikel (University of Cologne), Sibel Gün (University of Cologne), and Susanne Rölle-Höhne is greatly appreciated and acknowledged. This manuscript contains parts of a doctoral thesis by CG. 
Contributors FG, ES and SR planned the study. FG, DD, CG, TV and TK performed study procedures, acquired and analysed data. RB performed WBV and instructed patients. MH performed statistical analyses. FG, ES, SB and SR wrote and approved the manuscript.

Funding Actelion Pharmaceuticals (unrestricted research grant).

Competing interests None declared.

Patient consent Obtained.

Ethics approval Ethics Committee of the University of Cologne.

Provenance and peer review Not commissioned; externally peer reviewed.

Open Access This is an Open Access article distributed in accordance with the Creative Commons Attribution Non Commercial (CC BY-NC 4.0) license, which permits others to distribute, remix, adapt, build upon this work non-commercially, and license their derivative works on different terms, provided the original work is properly cited and the use is non-commercial. See: http://creativecommons.org/ licenses/by-nc/4.0/

\section{REFERENCES}

1 Galiè N, Humbert M, Vachiery JL, et al. 2015 ESC/ERS Guidelines for the diagnosis and treatment of pulmonary hypertension: The Joint Task Force for the Diagnosis and Treatment of Pulmonary Hypertension of the European Society of Cardiology (ESC) and the European Respiratory Society (ERS). Endorsed by: Association for European Paediatric and Congenital Cardiology (AEPC), International Society for Heart and Lung Transplantation (ISHLT). Eur Heart J 2016;37:67-119.

2 Rosenkranz S. Pulmonary hypertension 2015: current definitions, terminology, and novel treatment options. Clin Res Cardiol 2015;104:197-207.

3 Pulido T, Adzerikho I, Channick RN, et al., for the SERAPHIN Investigators. Macitentan and morbidity and mortality in pulmonary arterial hypertension. N Engl J Med 2013;369:809-18.

4 Galiè N, Barberà JA, Frost $A$, et al. Initial use of Ambrisentan plus Tadalafil in pulmonary arterial hypertension. N Eng/ I Med 2015;379:834-44.

5 Sitbon 0 , Channick R, Chin KM, et al. Selexipag for the treatment of pulmonary arterial hypertension. N Engl J Med 2015;373:2522-33.

6 Mereles D, Ehlken N, Kreuscher S, et al. Exercise and respiratory training improve exercise capacity and quality of life in patients with severe chronic pulmonary hypertension. Circulation 2006:114:1482-9.

7 Weinstein AA, Chin LMK, Keyser RE, et al. Effect of aerobic exercise training on fatigue and physical activity in patients with pulmonary arterial hypertension. Respir Med 2013:107:778-84.

8 Chan $\mathrm{L}$, Chin $\mathrm{LM}$, Kennedy $\mathrm{M}$, et al. Benefits of intensive treadmill exercise training on cardiorespiratory function and quality of life in patients with pulmonary hypertension. Chest 2013;143:333-43.

9 de Man FS, Handoko ML, Groepenhoff $\mathrm{H}$, et al. Effects of exercise training in patients with idiopathic pulmonary arterial hypertension. Eur Respir J 2009:34:669-75.

10 Ehlken $\mathrm{N}$, Lichtblau $\mathrm{M}$, Klose $\mathrm{H}$, et al. Exercise training improves peak oxygen consumption and haemodynamics in patients with severe pulmonary arterial hypertension and inoperable chronic thromboembolic pulmonary hypertension: a prospective, randomized, controlled trial. Eur Heart J 2016;37:35-44.

11 Grünig E, Ehlken N, Ghofrani $A$, et al. Effect of exercise and respiratory training on clinical progression and survival in patients with severe chronic pulmonary hypertension. Respiration 2011:81:394-401.

12 Rittweger J, Beller G, Felsenberg D. Acute physiological effects of exhaustive whole-body vibration exercise in man. Clin Physiol 2000;20:134-42.

13 Bosco C, Colli R, Introini E, et al. Adaptive responses of human skeletal muscle to vibration exposure. Clin Physiol 1999;19:183-7.
14 Pérez-Turpin JA, Zmijewski P, Jimenez-Olmedo JM, et al. Effects of whole body vibration on strength and jumping performance in volleyball and beach volleyball players. Biol Sport 2014;31:239-45

15 Bruyere O, Wuidart MA, Di Palma E, et al. Controlled whole body vibration to decrease fall risk and improve health-related quality of life of nursing home residents. Arch Phys Med Rehabil 2005:86:303-7.

16 Álvarez-Barbosa F, del Pozo-Cruz J, del Pozo-Cruz B, et al. Effects of supervised whole body vibration exercise on fall risk factors, functional dependence and health-related quality of life in nursing home residents aged $80+$. Maturitas 2014;79:456-63.

17 O'Keefe K, Orr R, Huang $P$, et al. The effect of whole body vibration exposure on muscle function in children with cystic fibrosis: a pilot efficacy trial. I Clin Med Res 2013:5:205-16.

18 Kantele S, Karinkanta S, Sievänen H. Effects of long-term whole-body vibration training on mobility in patients with multiple sclerosis: a meta-analysis of randomized controlled trials. J Neurol Sci 2015;358:31-7.

19 Greulich T, Nell C, Koepke J, et al. Benefits of whole body vibration training in patients hospitalised for COPD exacerbations - a randomized clinical trial. BMC Pulm Med 2014;14:60

20 Furness T, Joseph C, Naughton G, et al. Benefits of whole-body vibration to people with COPD: a community-based efficacy trial. BMC Pulm Med 2014;14:80.

21 Rauch F, Sievanen H, Boonen S, et al. Reporting whole-body vibration intervention studies: recommendations of the International Society of Musculoskeletal and Neuronal Interactions. J Musculoskelet Neuronal Interact 2010:10:193-8.

22 Rosenkranz S, Preston IR. Right heart catheterization: best practice and pitfalls in pulmonary hypertension. Eur Respir Rev 2015;24:642-52.

23 Rosenkranz S, Gibbs JSR, Wachter R, et al. Left ventricular heart failure and pulmonary hypertension. Eur Heart J 2016:37:942-54

24 Lang RM, Badano LP, Mor-Avi V, et al. Recommendations for cardiac chamber quantification by echocardiography in adults: an update from the American Society of Echocardiography and the European Association of Cardiovascular Imaging. Eur Heart I Cardiovasc Imag 2015;16:233-71.

25 ATS Committee on Proficiency Standards for Clinical Pulmonary Function Laboratories. ATS statement: guidelines for the six-minute walk test. Am J Respir Crit Care Med 2002;166:111-17.

26 Wasserman K, Hansen JE, Sue DY, et al. Measurements During Integrative Cardiopulmonary Exercise Testing. In: Principles of Exercise Testing and Interpretation. 5th edn. Philadelphia: Lippincott Williams \& Wilkins, 2012:71-103.

27 Fricke 0 , Weidler J, Tutlewski B, et al. Mechanography: a new device for the assessment of muscle function in pediatrics. Pediatr Res 2006;59:46-9.

28 Mathai SC, Puhan MA, Lam D, et al. The minimal important difference in the 6 minute walk test for patiens with pulmonary arterial hypertension. Am J Respir Crit Care Med 2012;186:428-33.

29 Ghofrani HA, Galiè N, Grimminger F, et al., for the PATENT Investigators. Riociguat for the treatment of pulmonary arterial hypertension. N Engl I Med 2013:369:330-40.

30 Rosenberger A, Liphardt AM, Bargmann A, et al. EMG and heart rate responses decline within 5 days of daily whole-body vibration training with squatting. PLoS ONE 2014;9:e99060.

31 Gloeckl R, Heinzelmann I, Seeberg S, et al. Effects of complementary whole-body vibration training in patients after lung transplantation: a randomized, controlled trial. J Heart Lung Transplant 2015;34:1455-61.

32 Perchthaler D, Grau S, Hein T. Evaluation of a six-week whole-body vibration intervention on neuromuscular performance in older adults. I Strength Cond Res 2015;29:86-95.

33 Kabitz HJ, Bremer HC, Schwoerer A, et al. The combination of exercise and respiratory training improves respiratory muscle function in pulmonary hypertension. Lung 2014;192:321-8. 